\title{
A Violência Doméstica e Racismo Contra Mulheres Negras
}

\author{
Christiane Carrijo' (iD) 0000-0002-1486-7006 \\ Paloma Afonso Martins' (D) 0000-0002-9082-6660 \\ 'Universidade Estadual Paulista “Júlio de Mesquita Filho", Departamento de Psicologia, \\ Bauru, SP, Brasil. 17033-360
}

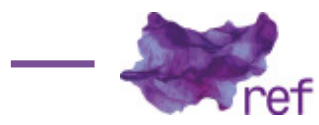

Resumo: A pesquisa qualitativa realizada com três mulheres negras vítimas de violência doméstica procurou verificar, por meio de entrevistas, se existiram inscrições da introjeção do ideal de brancura em suas subjetividades e avaliar em que contextos apareceram o racismo e a violência doméstica em suas vidas. A importância desse tipo de estudo está em destacar a existência do mito da democracia racial no Brasil, em sua face perversa, ao demonstrar como o ideal de ego de brancura é veiculado inconscientemente por meio da ideologia como forma de subalternizar o grupo étnico-racial negro ao dominante. Coloca-se em destaque o alto índice de violência doméstica contra mulheres negras e a urgência de políticas públicas para a prevenção desses crimes e proteção às vítimas.

Palavras-chave: mulheres negras; racismo; violência doméstica; ideal de ego; psicanálise.

Domestic Violence and Racism against Black Women

Abstract: This qualitative research study, which involved interviews with black women victims of domestic violence, was aimed at verifying if there were any inscriptions of the ideal of whiteness introjected in their subjectivities and at evaluating the contexts in which racism and domestic violence appear in their lives. The importance of this type of study is in highlighting the existence of the myth of racial democracy in Brazil, in its perverse face, by showing how the ego ideal of whiteness is propagated unconsciously through ideology as a way of subjugating the black racial-ethnic group to the dominant one. The study emphasizes the high rate of domestic violence against black women and the urgency of public policies for the prevention of these crimes and the protection of the victims.

Keywords: Black Women; Racism; Domestic Violence; Ego Ideal; Psychoanalysis.

\section{Introdução}

Esse artigo foi redigido a partir de uma pesquisa cujo objetivo geral foi verificar as inscrições da introjeção do ideal de brancura na constituição subjetiva de mulheres negras vítimas de violência doméstica. Poucas pesquisas colocam em questão a apropriação do corpo negro como elemento de sofrimento psíquico e de desequilíbrios narcísicos. A relevância destes estudos é a compreensão de como a introjeção desse modelo de racismo ajuda na tentativa de subalternizar o grupo étnico-racial negro ao dominante. A violência racista subtrai do sujeito a possibilidade de explorar e extrair todo o infinito potencial de criatividade, beleza e prazer de que ele é capaz; em mulheres negras soma-se a isso a violência de gênero.

Também foi objeto de investigação avaliar a presença da violência do racismo e da violência doméstica na história de vida das mulheres negras entrevistadas. A metodologia científica dessa pesquisa qualitativa foi dividida em duas etapas. A primeira, uma revisão de textos freudianos para pesquisar o conceito de ideal de ego e um breve estudo sobre o racismo e a violência doméstica. A segunda contou com a elaboração do termo de consentimento livre e esclarecido e realização de entrevistas semiestruturadas com três mulheres voluntárias. Com as entrevistas 
individuais foram investigados o racismo e a violência doméstica e se construiu três eixos para analisar o material: o primeiro, como as participantes se veem; o segundo, como elas veem a negritude no outro (família e desconhecidos), e terceiro eixo, a violência doméstica. Com os dados obtidos nesse procedimento, foram feitas categorias de análise (Laurence BARDIN, 2009) a partir dos discursos das mulheres participantes, procurando, com isto, construir narrativas que possibilitassem a visualização dos objetivos propostos. No artigo descrevemos uma parte do trabalho realizado nessa pesquisa.

\section{Racismo e Violência contra Mulheres Negras}

Os dados das pesquisas sobre violência denunciam uma "vertente" específica e velada, o racismo, e apontam com urgência a necessidade de estudos voltados para a população negra, pois, embora esta seja majoritariamente violentada, é invisível socialmente. Em diversos países, as mulheres negras aparecem como maioria das vítimas nos índices de violações de direitos humanos - o Brasil não é diferente. Em nosso país, mulheres negras são 53,6\% das vítimas de mortalidade materna (considerada por especialistas uma ocorrência evitável com acesso a informações e atenção do pré-natal ao parto), $65,9 \%$ das vítimas de violência obstétrica e $68,8 \%$ das mulheres mortas por agressão. No ano de 2013 , houve uma queda de $9,8 \%$ no total de homicídios de mulheres brancas, enquanto os homicídios de negras aumentaram 54,2\% (INSTITUTO PATRíCIA GALVÃO, 2016). A análise desses números levanta a hipótese de que mulheres negras não contam efetivamente com o apoio do Estado (Suelaine CARNEIRO, 2017).

Segundo dados da Secretaria Especial de Políticas para as Mulheres (SPM), no primeiro semestre de 2016, os atendimentos do Ligue 180 indicaram um total de 555.634 ligações, das quais $59,71 \%$ foram feitas por mulheres negras, a maioria das denúncias feita pela própria vítima $(67,9 \%)$. Esse dado assusta e converge com a literatura, no que tange à solidão da mulher negra. Para Claudete Souza (2008), essa solidão é uma experiência "individual, comunitária e coletiva, pois faz parte de uma construção histórica, social e política cravada pela dimensão de gênero e étnico-racial" (p. 57). Ferreira (2018) afirma que essa solidão não se estabelece apenas por meio de relações sexuais, mas também afetivas entre as mulheres e suas famílias, denunciando uma rejeição afetiva permeada por ideais impostos socialmente (Lorena FERREIRA, 2018). Dependência financeira do parceiro e ausência de rede de apoio ou vínculo familiar são fatores de risco para violência doméstica; o primeiro deles, muitas vezes uma consequência explícita de racismo (dificuldade de inserção no mercado de trabalho por serem mulheres negras), constituindo violências que se sobrepõem. Percebe-se que, hoje, vitimiza-se seletivamente. Com relação à denúncia de violências e à Lei Maria da Penha, mulheres brancas costumam ser mais bem atendidas, enquanto as negras são deixadas de lado (as taxas de violência contra brancas tendem a baixar enquanto contra negras tendem a aumentar). Há toda uma estrutura de segregação e seletividade da violência (Rute PINA, 2016).

A respeito da violência contra mulher, Lourdes Bandeira (2014) afirma que esse tipo de violência não se refere a atitudes e pensamentos de aniquilação de alguém considerado como igual e visto nas mesmas condições de existência e valor como aquele que a pratica. Pelo contrário, a motivação da violência seria as expressões de desigualdades baseadas na condição de sexo, que começa no seio familiar, onde as relações de gênero se constituem por meio de hierarquia. Porém, não se negam as situações em que marcas de raça, idade, classe, dentre outras, modificam a posição em relação àquela do núcleo familiar (BANDEIRA, 2014).

Violências como o machismo e o racismo servem a um propósito maior de desumanizar as mulheres, negar-lhes a condição de pessoas e transformá-las em "coisas"; daí os apelidos "animalescos" como "bicha fedorenta", "macaca", "gambá". A despersonalização é levada ao real quando muitas mulheres procuram os órgãos de proteção sem a posse de seus próprios documentos e nem os dos filhos: foram rasgados, queimados ou estão em poder dos seus agressores. A falta de documentos, simbolicamente, é atestar sua inexistência e a privação da autoridade sobre seus filhos (Benilda BRITO, 1997).

Uma das formas nas quais o racismo aparece em casos de violência contra mulher é em relação à sexualidade. Lia Zanotta Machado e Maria Tereza Magalhães (1998) apontam que durante conflitos, as acusações do homem recaem sobre a conduta sexual feminina na suspeita de traições. Esta desconfiança de traição foi considerada uma forma de racismo devido à "associação das mulheres negras à sexualidade desviante, porque exacerbada, e à prostituição [...] relatada também nas pesquisas de Burdick (1999), Moutinho (2004) e Giacomini (2006b)" (Bruna PEREIRA, 2013, p. 94).

Para José Moura Gonçalves Filho (2017), o racismo é eminentemente um fenômeno histórico, e, por conseguinte, social: a luta de um grupo contra outro. Assim, a humilhação de um negro é praticada de forma que nunca se restringe apenas a ele; o ataque a "um negro" é sempre um ataque à coletividade, a todos os negros. O ataque racista é um ataque exemplar, contra um grupo, e que representa os interesses do grupo que ataca. 
No Brasil, a ausência de recorte de gênero e racial em pesquisas na área de Psicologia e Psicanálise sobre o tema da violência é marcante, tal como nos debates políticos e teóricos. Todavia, é impossível negar que, se a violência de gênero atinge todas as mulheres, às negras e às indígenas ainda se acrescenta uma violência de outra natureza: a violência racial/étnica. A soma de ambas resulta em potencialização mútua, o que indica a necessidade de atenção diferenciada na abordagem, no enfrentamento e nas soluções (Fátima OLIVEIRA, 2003).

Jackeline Romio (2013) ressalta a necessidade de se ampliar a compreensão das variáveis atuantes na violência contra as mulheres, assim como das especificidades da violência doméstica no caso de mulheres negras, que estão expostas a diversos fatores de risco, tais como: conflitos familiares, intolerância religiosa, vulnerabilidade social devido ao perigo nas áreas onde elas residem, racismo, desigualdades socioeconômicas, violências sexuais, conflitos nas relações conjugais-afetivas-sexuais, falta de segurança na sociedade em geral, além da extrapolação da violência conjugal para além do matrimônio e demais particularidades.

Os casos de violência doméstica têm $58,86 \%$ de mulheres negras como vítimas. Pesquisas apontam que a violência doméstica e familiar contra mulheres negras é um fenômeno complexo constituído por diversos fatores que amplificam um ao outro (OLIVEIRA, 2004, p. 44-49; Jurema WERNECK, 2010). A violência de gênero, por exemplo, adiciona-se à violência racial/étnica, o que, para além de sua soma, as potencializa mutuamente (OLIVEIRA, 2004). Werneck (2010) entende que, nessa amálgama, o racismo está ancorado no capitalismo e no patriarcado, o que dá uma singularidade histórica, política e também referente à sociedade sobre a qual ele incide. Para a autora, portanto, seria necessário enfrentar os aspectos estruturais da violência em seu conjunto, uma vez que cada tipo de violência a que as mulheres negras estão expostas se associa aos demais, agindo de forma exponencial, sobrepondo violências e vulnerabilidades. Ainda segundo a autora, o principal erro das (poucas) pesquisas realizadas nesta área foi abordar de forma isolada cada tipo de violência, com forte apelo para a violência doméstica, inviabilizando o enfrentamento dos demais vetores de violência e a articulação entre eles (WERNECK, 2010).

Vivenciar a violência doméstica configura-se, na grande maioria das vezes, um trauma. Para Gabriela Lima e Blanca Werlang (2011), o trauma vai contra as tentativas de elaboração e inscrição psíquica; em outras palavras, diz respeito a uma dor impossível de ser representada psiquicamente e tem como consequência um forte impacto no processo de subjetivação. Quando a angústia e a dor deste trauma atingem um nível insuportável, surge no sujeito um sentimento de ruptura do eu, o qual se aproxima da vivência de morte. Como o excesso que o caracteriza não consegue ser elaborado, o ato passa a ser a única via de expressão. Sándor Ferenczi (1992) aponta que a criança que vivencia desprazer, mais tarde, em virtude da compulsão à repetição, pode revivê-lo incessantemente.

\section{Aspectos Psicossociais}

É importante investigar como a violência do racismo age no psiquismo de suas vítimas, pois ele também tem sua faceta simbólica. Para isso, contamos com revisão da literatura, buscando na raiz, nos processos formadores da identidade do sujeito, quais as possíveis implicações, para as pessoas negras, de se crescer e se formar em uma sociedade racista.

Segundo Jean Laplanche e Jean-Bertrand Pontalis (1995), o Ideal de Ego é uma instância da personalidade resultante do narcisismo infantil aliado às identificações com os pais, seus substitutos e ideais coletivos; é um modelo a que o sujeito procura conformar-se. Jurandir Costa (1986) acrescenta que sua função ideal é favorecer o surgimento de uma identidade do sujeito pautada em seu investimento erótico no próprio corpo. "Entretanto, o modelo de identificação normativo-estruturante com o qual o sujeito negro se defronta é o de um fetiche: o fetiche do branco, da brancura" (COSTA, 1986, p. 106).

A primeira face da violência racista tende a destruir a identidade do sujeito negro, motivando uma perseguição ao próprio corpo. Através da internalização de um Ideal de Ego branco, o sujeito negro é obrigado a formular para si um projeto identificatório incompatível com as propriedades biológicas do seu corpo, o qual tenta alcançar mesmo à custa de sua felicidade, quando não de seu equilíbrio psíquico (COSTA, 1986). Realizar o Ideal de Ego é uma exigência do Superego; a medida de harmonia interna do indivíduo é dada pelo nível de aproximação entre o Ego atual e o ldeal de Ego (Neusa SOUZA, 1983). Todo ideal identificatório do negro, se ele estiver identificado com o ideal da brancura, converte-se em um ideal de retorno ao passado, onde ele poderia ter sido branco, ou na projeção de um futuro no qual seu corpo e identidade negros desaparecerão. Este processo culmina em um futuro no qual deixa de existir: sua aspiração é a de não ser ou não ter sido; o negro, no desejo de embranquecer, acaba por desejar a própria extinção (COSTA, 1986).

A ideologia de cor mostra-se como sendo a superfície de uma ideologia de corpo. Se o primeiro traço da violência racista é a identificação do negro com um Ideal de Ego branco, a segunda é estabelecer, por meio do preconceito de cor, uma relação persecutória entre o sujeito 
negro e seu corpo. O terceiro elemento fica a cargo do pensamento negro, que parasitado pelo racismo, termina por fazer do prazer um elemento secundário para o corpo e mente. Assim, neste tipo de trajetória psíquica e inconsciente, para o psiquismo negro em ascensão, o importante não é pensar e ver o que poderia vir a dar-lhe prazer, mas o que é desejável pelo branco. Como o branco não deseja o corpo negro, o pensamento se encarregará para que este inexista enquanto representação mental (COSTA, 1986). Na construção de um Ideal de Ego branco, a primeira regra básica é a negação, por parte do negro: o expurgo de qualquer "mancha negra" (SOUZA, 1983).

A respeito do conceito de identidade, Sigmund Freud (1969) deixou alguns caminhos, embora não tenha deixado uma conclusão, pois usou esse sentido várias vezes durante sua obra, mas não teorizou sobre ele. A filosofia também traz sua noção de identidade, a qual se refere a uma instância de si mesmo. Michel Foucault (1994), na contramão, mostra que o processo de construção deste "si mesmo" pode ser acompanhado historicamente, de acordo com os modos de cuidado e conhecimento de si que marcam a história da humanidade ocidental. De volta à psicanálise, Eduardo Cunha (2000) propõe que é no campo privado das fantasias que o sujeito vai, aos poucos, construindo sua singularidade, usando para isso os modelos aprendidos com aqueles com os quais se identifica e quem Ihes forneceu palavras e afeto necessários para o desenvolvimento (CUNHA, 2000).

Renato Mezan (1986) afirma identidade como um elemento que vai sendo adquirido aos poucos e que se situa no cruzamento entre algo que vem de nós, referindo-se ao nosso psiquismo, e algo que nos vem de fora, a realidade externa. A identidade pessoal, para o autor, constrói-se no convívio com os outros. Acrescenta que, segundo Freud, em Totem e Tabu, na realidade externa o que existe é a sociedade humana, com suas normas e instituições (MEZAN, 1986).

Kimberlé Williams Crenshaw (2002) construiu o conceito de interseccionalidade para explicar as intersecções entre diversos fenômenos de subordinação e discriminação. Nas suas palavras:

A associação de sistemas múltiplos de subordinação tem sido descrita de vários modos: discriminação composta, cargas múltiplas, ou como dupla ou tripla discriminação. A interseccionalidade é uma conceituação do problema que busca capturar as consequências estruturais e dinâmicas da interação entre dois ou mais eixos da subordinação. Ela trata especificamente da forma pela qual o racismo, o patriarcalismo, a opressão de classe e outros sistemas discriminatórios criam desigualdades básicas que estruturam as posições relativas de mulheres, raças, etnias, classes e outras. Além disso, a interseccionalidade trata da forma como ações e políticas específicas geram opressões que fluem ao longo de tais eixos, constituindo aspectos dinâmicos ou ativos do desempoderamento (CRENSHAW, 2002, p. 177).

Crenshaw (2002) apontou a necessidade de se atentar para as várias formas pelas quais o gênero se intersecta com outras identidades e de que maneira essas intersecções tornam determinados grupos mais vulneráveis, como, por exemplo, a marginalização específica de mulheres de grupos étnicos ou raciais e as lacunas de informação sobre elas. A pesquisadora aponta que ainda não se conhece por completo a realidade da vulnerabilidade interseccional de mulheres de grupos étnicos. O gênero não é o único fator de discriminação e precisa ser estudado com outros fatores conjuntamente, como raça e classe, os quais não são variáveis independentes, mas, sim, que se articulam.

Raquel Barreto (2018) escreve que, para Lélia Gonzalez, o racismo é uma construção ideológica com benefícios sociais e econômicos para os brancos de todas as classes e que a cultura brasileira é negra.

Lélia Gonzalez (2018) destacou o papel da mulher negra na constituição da identidade brasileira como negra e a articulação do duplo fenômeno do racismo e do sexismo:

Para nós o racismo se constitui como a sintomática que caracteriza a neurose cultural brasileira. Nesse sentido, veremos que sua articulação com o sexismo produz efeitos violentos sobre a mulher negra em particular [...] Trata-se das noções de mulata, doméstica e mãe preta (GONZALEZ, 2018, p. 191-192).

Para sair da reprodução e repetição de modelos da mulher negra a partir de textos que a abordavam numa perspectiva socioeconômica e revelavam a complexidade dos problemas raciais, Gonzalez (2018) propôs lidar com o resto que, segundo ela, desafiava as explicações. A mulata desvela o lugar da violência sexual, racial e de gênero das negras estupradas pelos senhores da casa grande e do Carnaval como a grande festa nacional que atualiza com força simbólica o mito da democracia racial, recaindo especialmente na mulher negra; a empregada doméstica denuncia a outra face da mesma violência. Mulata e empregada doméstica são o mesmo sujeito, vítimas da violência racista e sexista.

É na figura da mãe preta que Lélia Gonzalez dirá, com a colaboração do referencial lacaniano, que a verdade surge da equivocação; ela é a mãe, a que amamenta e cuida, conta histórias e ensina a falar as crianças brancas e, assim, exerce a função materna e subverte a raça dominante e, por isso, nossa língua é o pretuguês: 
Essa criança, esse infans, é a dita cultura brasileira, cuja língua é o pretuguês. A função materna diz respeito à internalização de valores, ao ensino da língua materna e a uma série de outras coisas mais que vão fazer parte do imaginário da gente. Ela passa pra gente esse mundo de coisas que a gente vai chamar de linguagem. E graças a ela, ao que ela passa, a gente entra na ordem da cultura, exatamente porque é ela quem nomeia o pai (GONZALEZ, 2018, p. 205).

Gonzalez (2018) está interessada em compreender em como se deu a identificação do dominado com o dominador pois, para ela, o racismo é um sintoma introjetado que se deve, em parte, pelo que vivem os brasileiros ao se desejarem e se projetarem brancos ou descendentes de europeus. Alex Ratts e Flávia Rios (2010) apontam que Gonzalez, assim como outros autores, chamará esse processo de "embranquecimento" ou "branqueamento":

Abdias Nascimento, em Genocídio do negro brasileiro (1978), compara-o às noções de assimilação e aculturação, e lista elementos que o compõem: a ausência de memória e da história da África e de referências adequadas ao africano e ao negro no sistema educacional, incluindo a universidade; a "estética da brancura", ou seja, a predileção pelo modelo branco de beleza, arte e cultura e a concomitante rejeição no que se refere ao africano e ao negro; a insistência na interpretação das relações raciais brasileiras como harmônicas e sem espaço para expressão política e cultural negra; a reprodução de estereótipos raciais (e sexistas); e, por fim, o desejo de ser o Outro: branco, europeu, colonizador, ocidental (RATTS; RIOS, 2010, p. 4344).

Nesse bojo, podemos ampliar nossa reflexão sobre os efeitos da violência simbólica do racismo nas identidades, que podem se manifestar tempos depois, sob a forma de sintomas que a própria pessoa pode não reconhecer como tendo alguma relação causal com experiências de humilhação, exclusão e discriminação (Maria Lúcia da SILVA, 2017); daí a dificuldade do tema tratado nesta pesquisa.

Para Souza (1983), o contexto familiar é o lugar a partir do qual o ldeal de Ego é constituído; depois, é nas experiências de vida na escola, no trabalho etc. que será reforçado o ldeal de Ego, cujas vigas já foram erigidas, adquirindo significado e eficácia de modelo ideal para o sujeito. Numa sociedade multirracial, racista e de hegemonia branca, o a posteriori se produz no momento em que o negro enfrenta as condições concretas de opressão em que está imerso.

Sabe-se que o sujeito se constitui pelo olhar do outro. É de se pensar a hipótese de que o primeiro momento em que o bebê vivencia os efeitos do racismo é no contato com o desejo e o olhar das figuras parentais, olhar esse que poderá ser reforçado posterior e incessantemente pelos diferentes olhares que encontrará ao longo de seu desenvolvimento. As representações pejorativas influenciam a psique da criança negra e são nocivas, pois a ensinam a ter um olhar degradante sobre si mesma. O psiquismo existe em um corpo atacado a todo tempo por olhares, apelidos pejorativos, chacotas, xingamentos e até agressões físicas (SILVA, 2017). Essas agressões são praticadas não apenas por pares da mesma idade, mas até partindo de adultos para com crianças, como no caso recente onde a filha dos atores globais Bruno Gagliasso e Giovanna Ewbank, uma garotinha negra de apenas três anos, foi vítima de comentários racistas feitos por uma pessoa em um vídeo compartilhado publicamente em uma rede social, em novembro de 2017 (O GLOBO, 2017).

Para muitas pessoas negras, carregar essa característica é vivido com muita dificuldade, uma vez que imagens negativas, construídas pelo poder discriminatório e veiculadas por meio de discursos sobre o que "é" ser negro foram absorvidas através da introjeção. Dessa maneira, tornase muito difícil conviver com um corpo socializado como feio, um cabelo socializado como ruim, e assim por diante (SILVA, 2017). A fim de que o trauma da discriminação seja assimilado, são necessárias acomodações psíquicas para que a vida se torne ao menos suportável (MEZAN, 1986).

Eliane Cavalleiro (1998), ao observar o término de um dia de aula, contabilizou um número três vezes maior de crianças brancas sendo beijadas pelas professoras em comparação às crianças negras: dez crianças brancas para três negras. No decorrer de seu trabalho de campo, a autora percebeu que as professoras faziam referência à cor da pele para diferenciar seus alunos, com dizeres como "moreninha, branquinha, japonesinho", embora não houvesse referências de crianças não brancas na sociedade brasileira nos cartazes e livros infantis expostos nos espaços de circulação na escola das crianças. Jean-Paul Sartre já apontou, em 1965, que os professores propagam centenas de hábitos de linguagem que afirmam a superioridade do branco sobre 0 preto; os alunos aprendem a dizer branco como a neve, para significar a inocência, e negrura de um olhar, de uma alma, de um crime (SARTRE, 1965). A escola tem sido o lócus para o surgimento da vergonha; segundo Vincent de Gaulejac (2006), a vergonha "incomoda, ela cria desconforto, é preferível evitá-la".

Silva (2017) coloca que o narcisismo da criança não é mais do que produto do narcisismo dos pais. Dessa maneira, perceber a importância do papel dos pais no processo de desenvolvimento do psiquismo do bebê e no adulto que ele será, assim como pensar o lugar que 
a criança ocupará na família, é de extrema importância para compreender o sujeito em sua totalidade; porém, isso ainda é insuficiente para explicar o efeito e o impacto do racismo na construção da identidade e nos processos de identificação (SILVA, 2017).

Ao se falar sobre identidade, é preciso considerar que ela é construída em um processo que se inicia com um complexo sistema de relações sociais existentes antes mesmo do nascimento do sujeito. Desse modo, identidade é uma questão política, uma vez que ninguém que viva em sociedade fica imune à ideologia, absorvendo-a, incorporando-a e a reproduzindo.

Marilena Chauí (2008) define ideologia como um fenômeno objetivo e subjetivo involuntário, produzido pelas condições objetivas da existência social dos indivíduos. É utilizada como recurso pela classe dominante para exercer dominação, de tal forma que ela continue em sua condição de privilégio, mas não seja vista dessa maneira pelos dominados. Para a autora, a ideologia burguesa irá produzir ideias que levam as pessoas a crerem que são desiguais em diferentes instâncias e por diversas razões, dentre as quais: por talentos; por desejo próprio (visto que aqueles que honestamente trabalham enriquecem e os preguiçosos empobrecem); por natureza (mas que a vida social, permitindo a todos o direito de trabalhar, dá-lhes iguais chances de melhorar); pelas condições sociais (mas que são iguais perante a lei e perante o Estado) (CHAUÍ, 2008). Dentre todos esses achismos, encontram-se escondidos fatos importantíssimos para compreender o contexto. São eles as oportunidades de trabalho que não são iguais para todos, uma vez que algumas pessoas oferecem seu trabalho e outras oferecem "vagas" para trabalhar, bem como a realidade na qual o Estado, apesar de democrático, defende, por meio da lei, os interesses da classe dominante, acabando, assim, com o princípio da igualdade.

O racismo consiste em caracterizar um conjunto humano ou justificar um comportamento do indivíduo como sendo decorrente da "raça" (etnia) à qual pertencem, usando atributos naturais/ raciais, os quais seriam os principais elementos que caracterizam moral e intelectualmente cada indivíduo. Assim, o racismo se coloca como uma ideologia e seria formado o pensamento racial, que coloca o domínio de um grupo sobre outro, como judeus, negros, muçulmanos, tendo como pauta única atributos negativos imputados a eles; em especial, com o uso de argumentos que se dizem científicos para afirmar essa divisão entre superiores e inferiores, quando, na realidade, trata-se de relações de poder legitimadas pela cultura dominante, levando à discriminação e à perseguição daqueles considerados inferiores (MUNANGA apud CAVALLEIRO, 1998; SÃO PAULO, 2008; Michel WIEVIORKA, 2007).

A extrema identificação com os valores sociais dominantes promove um impedimento do encontro com o outro e forma um terreno propício para a introjeção do preconceito; este último, manifestação individual, mas de origem social, se dá nas relações a partir de generalizações já consagradas por meio de estereótipos da cultura. Assim, atitudes hostis para determinado objeto são tanto uma resposta de conteúdos psíquicos do sujeito preconceituoso quanto da cultura na qual ele vive. A cultura oferece valores que, ao serem introjetados, são mediados pelo indivíduo e, em certa medida, modificados por ele através de seu próprio filtro; isto significa que nem sempre os valores individuais são compatíveis com a realidade e, por esse motivo, o preconceito está relacionado mais a aspectos psíquicos da formação do eu, que ativa o mecanismo de defesa da introjeção, do que a características supostamente existentes no alvo do preconceito (CROCHIK apud Marian FERRARI, 2006).

Retomando a colocação de Maria Beatriz Vanucchi (2017), na qual a violência social é uma construção que visa atender necessidades de autoconservação dos grupos, a autora afirma, nesse contexto, que nem a instituição do Direito, cuja função é assegurar igualdade por meio da regulação dos excessos, consegue incluir a todos. Os motivos são a interdição dos impulsos destrutivos que nunca chega a eliminar a pressão destes, pois o que é reprimido retorna, e também porque a lei é feita por pessoas, das quais as com maior poder e visibilidade legislam e executam as normas que garantem seus interesses. Portanto, a lei sempre deixa a marca do exercício de dominação, que persiste como elemento irredutível nas relações humanas. Uns sempre têm mais proteção e pertença que outros, e isso, por conseguinte, gera a determinação de quem tem ou não valor para o grupo, fazendo destes últimos "bodes expiatórios"; contra estes, é permitida a descarga de agressividade (VANUCCHI, 2017).

Disso decorre que cada formação coletiva faz suas vítimas e define um alvo para sua violência. Desse modo, seria ingenuidade ou idealização pensar em uma proposta de organização social que erradique a brutalidade da humanidade, embora isso não signifique que não devamos intervir nos processos que culminam em determinados modos e configurações que a violência adquire em diferentes formações sociais (VANUCCHI, 2017). Esse é um compromisso ético que compreende as produções humanas como sendo mutáveis e de dimensão política.

A sociedade provoca muitos traumas nos sujeitos negros ao lhes negar o reconhecimento das consequências históricas dos quais são sobreviventes. Kabengele Munanga (2017) atesta que o racismo brasileiro desmobiliza suas vítimas, diminuindo a coesão ao dividi-las entre negros e pardos. Ao criar essa ambiguidade dos mestiços, dificulta o processo de formação de sua identidade, pois 
muitos ainda não se encontram politizados e conscientizados, deixando de assumir sua negritude e preferindo o ideal do branqueamento, que segundo creem, possibilitaria vantagens exclusivas da branquitude. Além disso, a figura das pessoas mestiças é muito manipulada pela ideologia racial brasileira com os fins de escamotear problemas da sociedade e combater propostas de políticas afirmativas que beneficiam aqueles que se assumem negros (MUNANGA, 2017).

Assim, a dor em carne viva desses traumas provoca silêncio, grito e choro. Muitas vezes, a estratégia psíquica utilizada é de capturar o pensamento para o trabalho psíquico de evitar $\circ$ sofrimento. Entretanto, a denegação do racismo nos discursos vigentes também coloca a dúvida quanto à veracidade da violência causada por gestos e falas que reafirmam a estratificação social. O não dito, mas que é atuado pela exclusão social em diversas situações recorrentes, como nas ruas, portarias de prédios e lugares cujo acesso é restrito indiretamente a brancos, pode culminar no limite da experiência de desrealização. Dar voz a isso que está emudecido é movimentar a esfera das representações, de como são feitas as imagens, testemunhar e tratar desse pesadelo social. A violência cotidiana do "racismo cordial", típico da brasilidade, nega a negritude e mantém o negro na condição de vítima da violência. Ao escolher politicamente afirmar sua negritude, os movimentos militantes negros apresentam um ponto de partida para a saída dessa condição de vitimização: estabelecem diferentes linhas de força para além da dor, por meio da adoção de um projeto de identidade firmado na valorização de seus traços (VANUCCHI, 2017).

\section{Metodologia e breve descrição de resultados}

A metodologia científica dessa pesquisa é qualitativa e foi dividida em duas etapas. A primeira, um trabalho teórico sobre racismo, violência doméstica e o conceito de ideal de ego na psicanálise. A segunda contou com a assinatura do termo de consentimento livre e esclarecido e entrevista semiestruturada aplicada individualmente. Com os dados obtidos nesse procedimento, foram construídas categorias de análise (BARDIN, 2009) a partir dos discursos das mulheres participantes, procurando, com isto, construir narrativas que possibilitem a visualização dos objetivos propostos. Com as categorias, foram construídos três eixos para análise: o primeiro, como as participantes se veem; o segundo, como elas veem a negritude no outro (família e desconhecidos) e o terceiro eixo, a violência doméstica.

Foram realizadas entrevistas individuais com três participantes (nomeadas como A., AC. e J.) selecionadas junto à equipe profissional de um Centro de Referência da Mulher (CRM) de um município do interior paulista (Brasil); o critério: mulheres que fossem negras e vítimas de violência doméstica. No entanto, também foi possível perceber mais semelhanças entre as participantes: faixa etária (idades de 30 a 33 anos), baixa escolaridade (apenas uma delas concluiu o ensino fundamental e possuía ensino médio incompleto) e se encontravam, no momento das entrevistas, desempregadas ou em subempregos (a participante A. tentava vender títulos de capitalização no centro da cidade, recebendo um real por título vendido, sendo que tentou vender pães também, de casa em casa; AC. fazia faxinas, às vezes aceitando caixas de leite ou "a feira" - legumes, verduras - em troca de seu serviço).

Sobre a religião, também as três se disseram evangélicas; o número de filhos foi alto entre todas elas, porém, algumas crianças faleceram. Duas participantes tiveram seis filhos e uma delas, cinco, de companheiros diferentes, nos três casos. Esse dado é relevante, pois, em seus relatos, percebe-se que as crianças ficam sob a responsabilidade das mães, os pais não se fazendo muito presentes, deixando as situações de vida pessoal e profissional dessas mulheres mais difíceis e complexas. Devido ao número de pessoas que dependem delas para se sustentar financeiramente, a qualidade dos trabalhos aceitos por elas vai decaindo cada vez mais, desvalorizando o valor de sua mão de obra e gerando mais um fator de risco para a violência, que é a dependência econômica do parceiro. Para Lílian Santos (1999), a violência doméstica e familiar, ligada com o fator econômico, abre precedente para que as mulheres se sujeitem a atos violentos, por causa da dependência econômica que nutrem em relação a seus companheiros. Não dependendo financeiramente dos mesmos, as mulheres podem tornar-se mais respeitadas pelos parceiros e, também, sentirem-se seguras para romper um relacionamento conjugal violento (SANTOS, 1999). Sobre suas residências, duas participantes passaram pela Casa Abrigo, e uma mora nos fundos da casa da sogra. A respeito da moradia, duas dependiam de ajuda do município (uma estava na Casa Abrigo, outra tinha o aluguel subsidiado por benefício social); a terceira vivia em uma extensão de madeira feita na casa da sogra, com dois cômodos e um banheiro improvisados para sete pessoas.

Na história de vida das participantes, todas elas sofreram os seguintes tipos de violência: transgeracional, verbal, física e psicológica, e tinham histórico de violência familiar. Uma das participantes também sofreu violência patrimonial e duas delas passaram por tortura, juntamente com violência sexual.

Todas as entrevistadas relataram terem sofrido racismo ao longo da vida; uma delas, inclusive, no interior da própria família. Também existiram contradições a respeito dos ideais de 
beleza em mulheres e homens, como a descrição do que é a beleza não condizer com seus próprios traços ou a cor da pele ser descrita como "marrom" ou "morena".

A fim de dar lugar à voz dessas mulheres, será descrita de maneira mais detalhada uma das entrevistas, a da participante "J.". A violência transgeracional apareceu como uma repetição, pois sua mãe também sofreu violência doméstica, o pai batia nela constantemente e "J." assistia às cenas de agressão, que finalizaram quando o pai veio a falecer, por volta de seus cinco anos de idade. A mãe casou novamente e o padrasto também tentou agredi-la, além de xingar a participante "J." e os seus irmãos de pretos e macacos (violência verbal), sendo ele próprio negro. "J." se lembra de quando estava com 12 anos e o padrasto tentou bater na mãe; ela o desafiou, enfrentou e, desde esse dia, pararam as agressões, segundo a entrevistada porque o casal começou a frequentar a igreja e a mãe parou de beber.

Na infância, também sofreu violência por parte de um tio de 19 anos (moravam todos juntos com a avó), que batia em "J." e seus irmãos por ciúmes. Segundo suas palavras, "judiava com fósforo": colocava fósforos acesos entre os dedos dela e dos irmãos e dizia para que eles esperassem que o Batman iria aparecer. O tio também escolhia um irmão para bater e colocava um mais velho para assistir e dar risada, e depois revezava, quem assistiu apanhava e o outro teria de assistir e rir. Em outra violência descrita, o tio colocava os sobrinhos para gritar por detrás de um muro muito grande, e se ele não ouvisse, batia neles. Com relação ao seu segundo companheiro, "J." sofreu violência física, sexual, verbal e psicológica por parte dele e negligência e violência transgeracional por parte da sogra. Pedia ajuda a esta última, para que chamasse a polícia quando escutasse as agressões mas, nesses momentos, a senhora chamava o próprio filho e dizia para que não batesse na nora. Em uma ocasião, "J." perguntou à sogra: $X$., pelo amor de Deus, o que você está esperando acontecer para me ajudar, para chamar a polícia? O Y. vai me matar! ao que X. respondeu: Se ele te matar, eu abro mão dele. Quando o casal retornava para a própria casa, ele batia mais ainda na esposa, "J."

O companheiro de "J." a xingava de diversas formas durante as relações sexuais (violência verbal) e a obrigava ao sexo (violência sexual): Por que você não dá para mim? Por que você não quer dar para mim? Você tem outro! Você está dando para outro, sua vagabunda?; ela reagia e ele a agredia mais ainda.

As agressões físicas, segundo "J.", começaram pelo motivo de ciúmes de Y.; "J." reclamava das surras e o companheiro respondia que não doía, que ele também tinha apanhado assim na cadeia. Entre as agressões praticadas contra ela, estavam: queimar cigarro de maconha em sua pele, jogar água gelada e escarrar em seu rosto para mantê-la acordada. Ele a acordava com tapas na cara e gritava: por que você está dormindo? Você não gosta de mim? Não é para você dormir, é para você ficar comigo! Anda, me abraça!

Os ciúmes com agressões físicas apareceram também em uma cena descrita por ela, em que $Y$. a acusou de se insinuar para o inquilino e a agrediu fisicamente; ele the bateu na palma das mãos, nas solas dos pés, puxou-lhe o cabelo. Ela disse, durante a entrevista, que seu cabelo é longo, mas que, atualmente, tem pouco cabelo como consequência das agressões, e que quando ela penteia, mesmo que só com os dedos, caem vários fios. "J." contou a respeito de uma das vezes em que foi agredida por o companheiro acreditar que ela deixou uma almofada cair de propósito, na qual a mãe dele tropeçou. Disse que Y. ficou nervoso, mandou que "J." tirasse a almofada do chão, pegou-a pelos cabelos, fez com que ela beijasse os pés da sogra, gritando: Beija os pés da minha mãe, por que você não quer beijar? Minha mãe é uma rainha! Se ela tivesse caído e se machucado, eu matava você! Enquanto J. estava com a cabeça abaixada para beijar os pés, Y. pisava em sua cabeça.

Os ciúmes de Y. fizeram com que ele a acompanhasse em todas as suas consultas médicas, dizendo que não queria que o médico encostasse a mão nela. Ameaçava bater no médico se ele tocasse seu corpo. Por conta dessas ameaças, "J." passou a ser atendida por enfermeiras ao invés do médico obstetra.

Após o nascimento do filho, Y. tinha ciúmes do bebê. "J." relata que brincava com seu filho, levantava-o com as mãos, colocando-o no alto, de frente para o seu rosto e dizia a mamãe te ama! e que Y. o arrancava de seus braços, entregava para sua mãe, brigava com "J." e gritava o único amor da sua vida sou eu!, além de mandar que ela fosse para a casa debaixo, separando-a da criança. Nesse momento da entrevista, "J." chorou muito, fechou os olhos, colocou uma mão no rosto e parou de falar. Ficou alguns minutos assim; a entrevistadora procurou sua outra mão, acolheu-a e ficaram em silêncio. Desnecessário dizer a sensação de total desamparo sentida no ambiente e a ausência de palavras para dar conta do excesso de violência narrado até aquele momento.

Gostaríamos de acrescentar que Y. é o segundo companheiro de "J." Com o primeiro, chamaremos de L., também passou por muita violência. Ele bebia e saía com outras mulheres. Passou por quatro gestações; ele também a agredia fisicamente e chutava a barriga de "J.", que perdeu dois de seus filhos: um bebê foi natimorto e o outro chegou a nascer, mas viveu apenas um dia, vindo a óbito por falência múltipla dos órgãos. Esse companheiro morreu de câncer e era 
soropositivo. Apesar de não serem mais casados quando ele adoeceu, "J." ajudou a cuidá-lo em sua fase terminal e manteve os cuidados até seu falecimento. Contou isso com um sorriso nos lábios, como quem diz que, apesar de tudo o que aconteceu, permaneceu ao seu lado nesse momento final.

Com relação à sua experiência escolar, "J." relatou: eu não gostava muito porque era humilhada. Tenho bexiga baixa. O professor não deixava eu ir ao banheiro e quando eu fazia xixi na calça, ele me mandava escrever na lousa para todo mundo ver e rir de mim.

Com relação à sua descrição de mulher bonita, esta não parece consigo, exceto pela cor da pele, que ela diz "marrom" e o cabelo. Seu cabelo é longo, tal como da mulher ideal, e parece ser, de fato, muito importante para "J.". Em um dos encontros com a entrevistadora, mostrou que seu cabelo estava ralo devido às agressões de Y.; fazia isso com uma expressão de tristeza e inconformidade. Afirma não se achar bonita, diz que mudaria os dentes, colocaria silicone e que caçoam dela por ser magra, bem como por sua dentição; sente-se responsável pelas brincadeiras de mau gosto que sofre.

Em relação à sua negritude, "J." declara-se parda no começo da entrevista, quando fazíamos os dados sociodemográficos. Depois, no questionário sobre negritude, diz que sua família tem a pele negra e que a sua também é, e que se considera assim por conta do pai, descendente de índio, e sua mãe, negra. Em outro momento da entrevista, "J." diz que seu padrasto a xingava e, também aos irmãos, de macacos, mas que isso não fazia sentido, pois ele também era negro. "J." diz que ser negra não influencia em sua vida, mas afirma haver preconceito devido à cor das pessoas. Conta que a literatura aponta que a maioria das pessoas não se considera racista, mas conhece alguém que é, e que entre os negros, muitos afirmam não sofrer racismo, mas conhece pessoas que já passaram por isso.

Uma parte breve da narrativa de "J." ajuda-nos a dar forma ao grau de violência e de racismo presente em sua vida e auxilia a expressar as diferentes violências cometidas contra as mulheres dessa pesquisa. Entendemos que as histórias das outras entrevistadas não estão registradas neste artigo, porém poderão ser descritas em outro momento oportuno; no mais, pensamos que é preciso cuidado e delicadeza na construção dessas narrativas, todas de muita violência, exigindo uma redação que abarque a intensidade das experiências vividas por essas mulheres.

\section{Considerações finais}

As mulheres entrevistadas nessa pesquisa relataram histórias de vida com a presença do racismo e da violência doméstica e sempre com um intenso sofrimento e dificuldade de nomear suas vivências. Todas as entrevistadas narraram histórias de racismo na infância, duas delas sendo na escola, dado convergente com a literatura segundo Cavalleiro (1998) e que deveria colocar o país e os educadores em estado de alerta, uma vez que as escolas são o lugar de formação intelectual e de cidadãos, de frequência obrigatória em média de oito anos de estudos e que acabam por reproduzir ideais racistas.

Apenas uma participante relatou experiência de racismo no interior da própria família. As consequências psíquicas para a criança vítima de projeção dos pais são funestas e violentas, conforme explicitado neste artigo. Entende-se como projeção quando a família, imaginariamente, coloca nos filhos um ideal de beleza branca, seja para negar ou afirmar pejorativamente a negritude. No caso desta entrevistada, o racismo acontecia por meio de verbalizações degradantes, atacando seus traços físicos negroides e impactou a construção de sua identidade (SILVA, 2017).

Todas as entrevistadas sofreram violência verbal, psicológica e física cometidas por seus companheiros, bem como relataram violência transgeracional (presença de violência ao longo da história da genealogia familiar) e histórico de violência familiar em suas vidas. Duas, das três participantes, relataram tortura e violência sexual, lembrando que é alto o índice de mulheres negras vítimas de violência doméstica, que estas aparecem como a maioria dos casos, em oposição às mulheres brancas, cujos dados de violência decresceram (INSTITUTO PATRÍCIA GALVÃO, 2016).

No discurso das entrevistadas, é possível perceber que se veem como negras quanto à descrição da cor da pele. Contudo, aparecem complexidades nas narrativas, pois palavras como "morena mais escurinha", "pele marrom" etc. aparecem ao longo da entrevista e, também, algumas colocações indicando o desejo de alterações físicas que são compatíveis com um corpo branco, como: "afinaria o nariz", "cabelo liso" - que demonstram o ideal de ego sendo influenciado pela ideologia de embranquecimento da cultura. O próprio posicionamento das participantes em relação à sua "identidade racial" não é bem certo, exceto por uma delas, a qual se constatou a influência da presença de uma tia militante que a ensinou sobre uma positividade da negritude. Na entrevista, ao nomear pessoas que achavam bonitas, foram citadas cinco celebridades brancas, e quatro celebridades negras, o que podemos considerar, como hipótese, uma tentativa de equilibrar um ideal de ego e uma construção identitária mais próximos de uma autoimagem que mesclaria traços negroides com os valores sociais de beleza branca.

O Superego é construído, em parte, pelas imagos paternas (um esquema imaginário inconsciente que orienta seletivamente a forma como o sujeito apreende o outro) e, em parte, pela 
sociedade. Tem como exigência a realização do Ideal de Ego, que, por sua vez, é resultado do narcisismo infantil aliado às identificações com os pais. Dito isso, pode-se dimensionar o grau de sofrimento da pessoa negra submetida à exigência de um ideal identificatório da cor branca, incompatível consigo; mais ainda, quando se sabe que o conflito é externo, mediante as pressões e discriminações sociais e também conflito interno, intrapsíquico, pois existe um sofrimento sentido pelo indivíduo que percebe a diferença entre o ldeal de Ego e sua autoimagem quando esta é incompatível com a ideologia dominante da beleza associada ao branco. Lia Schucman e Mônica Gonçalves (2017) obtiveram em entrevistas um dado a respeito de pessoas que, embora se reconheçam como negras dentro de famílias inter-raciais, tentam minimizar seus traços negroides. Uma entrevistada relata que, com o aval da mãe, dormia com pregador no nariz, em sua infância, para afiná-lo. Nesse caso, tal como sua família, era preciso negar a negritude para legitimar o afeto. Para as autoras, na maioria dos casos, a família por amar, ou para amar o sujeito negro, muitas vezes, nega sua negritude. Em vez de reelaborarem o seu racismo para assim superá-lo, os familiares retiram a pessoa amada do grupo estigmatizado. Ela utiliza o conceito de "negação", de Freud, para interpretar esse comportamento (SCHUCMAN; GONÇALVES, 2017).

Concluindo, a investigação descrita neste artigo demonstra a importância de mais pesquisas que investiguem o sofrimento de pessoas negras vítimas de racismo, principalmente na escola, e também a maneira como essas pessoas incorporam o ideal de ego branco da cultura como maneira de se adaptar e, ao mesmo tempo, negar a violência que sofrem. Também é necessária a investigação do fenômeno da violência doméstica em mulheres negras para a melhoria de medidas protetivas e políticas públicas voltadas para as vítimas.

Ainda assim, também são imprescindíveis pesquisas e trabalhos interventivos que propiciem às pessoas negras uma política de resistência à violência que sofrem e, principalmente, uma conscientização do ideal de ego branco veiculado na cultura que Ihes permita ressignificarem sua cor, seu corpo e seu lugar social. Vanucchi (2017) afirma que há um longo caminho a ser percorrido e que esse começa com o uso da palavra. "Palavra para falar, testemunhar, ultrapassar a dor, usar a língua em sua função de ferramenta cultural, que pode desenhar outros destinos" (p. 68).

Cuti (2017) complementa que, tendo a palavra "negro" sido verbalizada para ofender, no momento em que o ofendido a assume e se diz negro, ele lhe dá outro significado, positivando o que era negativo. Se a palavra perde o poder de ofender, o ofensor perde um instrumento importante na prática da discriminação e na manutenção psíquica (o preconceito) do racismo. Ademais, a palavra "negro" nunca deixará em paz o ofensor porque convoca em si mesma o poder de lembrar uma história de opressão escravista e colonialista, desafiando a convicção da doença psíquica que é o racismo. Por essa argumentação, não empregar socialmente a palavra "negro" é brecar seu poder de transformação do significado negativo para o positivo, é abortar, nas palavras do autor, o processo iniciado pelos próprios negros na busca por sua cidadania (CUTI, 2017).

Reforça-se também a necessidade de políticas públicas que assumam a existência e a violência do racismo, que ajam no sentido de remediar os danos de tantos anos de opressão, e prevenam para o futuro. A convergência dos dados de Cavalleiro (1998) e dos discursos das participantes entrevistadas nesse trabalho, que apontam a reprodução da violência racista dentro das escolas, acaba por mostrar, também, que ali, nesse mesmo ambiente, deveria começar a luta contra o racismo. Sendo um combate à violência do racismo não apenas contra os negros, mas a todas as etnias que vivem no país, incentivando a valorização da diferença que cada povo traz em sua cultura, ensinando também respeito e tolerância.

Mulheres negras vítimas de violência doméstica necessitam de espaços psicoterapêuticos de acolhimento para contarem suas histórias e serem escutadas. Assim, ao ouvir suas próprias vozes, recordando lembranças, reconstroem suas vidas na teia de uma narrativa na qual o sofrimento é reconhecido e a violência é testemunhada por outra pessoa que a reconhece de fato. É possível voltar a caminhar, agora em outra direção? O árduo trabalho de lidar com a violência simbólica emaranhada nas entranhas do sujeito, fruto das identificações inconscientes e da opressão da dominação social de uma ideologia branca e europeia, está apenas começando. O processo psicoterapêutico é uma das faces necessárias para a luta dessas mulheres como trabalho de ressignificar o sofrimento e compreender o motivo do negro assimilar e reproduzir o que é eurobranco, mas, também, valorizar o que é afronegro. O outro lado dessa luta está nas escolas e nos bancos das universidades brasileiras, locais em que professores precisam dar espaço para essas histórias de violência e para denunciar o mito da democracia racial. Dessa maneira, a ideia de uma América africana ou Amefricana, de Lélia Gonzalez (2018), seria assumida como fazendo parte da identidade brasileira, na qual a influência da participação africana na formação cultural e social não é mais recalcada. Falamos português, mas, principalmente, pretuguês. 


\section{Agradecimentos}

Agradecemos à FAPESP pela bolsa de iniciação científica, ao Centro de Referência da Mulher pela colaboração na coleta de dados e às participantes que dividiram conosco suas histórias.

\section{Referências}

BANDEIRA, Lourdes Maria. "Violência de gênero: a construção de um campo teórico e de investigação". Revista Sociedade e Estado, Brasília, v. 29, n. 2, p. 449-469, maio/ago. 2014. Disponível em http://www.scielo.br/pdf/se/v29n2/08.pdf. Acesso em 03/07/2017.

BARDIN, Laurence. Análise de conteúdo. Lisboa: Edições 70, 2009. 281 p.

BARRETO, Raquel. "Lélia Gonzalez, uma intérprete do Brasil”. In: GONZALEZ, Lélia. Lélia Gonzalez Primavera para as rosas negras. São Paulo: Diáspora Africana, 2018. p. 12-27. (Coletânea organizada e editada pela UCPA União dos Coletivos Pan-Africanistas)

BRITO, Benilda Regina Paiva. "Mulher, negra, pobre. A tripla discriminação". Teoria e Debate, São Paulo, n. 36, p. 3-6, out. 1997.

CAVALLEIRO, Eliane dos Santos. Do silêncio do lar ao silêncio escolar: racismo, preconceito e discriminação na educação infantil. 1998. 240f. Dissertação (Mestrado em Educação) - Faculdade de Educação, Universidade de São Paulo, São Paulo, 1998.

CARNEIRO, Suelaine. Mulheres Negras e Violência Doméstica: decodificando os números. São Paulo: Geledés Instituto da Mulher Negra, 2017.

CHAUÍ, Marilena. O que é Ideologia. 2. ed. São Paulo: Brasiliense, 2008. 119p. (Coleção Primeiros Passos).

COSTA, Jurandir Freire. Violência e Psicanálise. 2. ed. Rio de Janeiro: Graal, 1986. 189p.

CRENSHAW, Kimberlé Williams. "Documento para o encontro de especialistas em aspectos da discriminação racial relativos ao gênero". Revista Estudos Feministas, Florianópolis, v. 10, n. 1, jan. 2002. Disponível em http://www.scielo.br/scielo.php?script=sci_arttext\&pid=S0104-026X200200010 0011 \&lng=pt\&tlng=pt. Acesso em 10/11/2018.

CUNHA, Eduardo Leal. "Uma interrogação psicanalítica das identidades". Caderno CRH, Salvador, n. 33, p. 209-228, 2000.

CUTI. "Quem tem medo da palavra negro". In: KON, Noemi Moritz; SILVA, Maria Lúcia da; ABUD, Cristiane Curi (Orgs.). O racismo e o negro no Brasil: questões para a psicanálise. São Paulo: Perspectiva, 2017. p. 197-212. (cap. 11)

FERENCZI, Sándor. "A criança mal acolhida e sua pulsão de morte". In: FERENCZI, Sándor. Obras completas de Sándor Ferenczi. São Paulo: Martins Fontes, 1992. p. 47-51.

FERRARI, Marian A. L. Dias. "O papel da diferença na construção da identidade". Boletim de Psicologia, São Paulo, v. 56, n. 124, p. 1-8, jun. 2006. Disponível em http://pepsic.bvsalud.org/scielo.php?script= sci_arttext\&pid=S000659432006000100002\&Ing=pt\&nrm=iso. Acesso em 11/12/2017.

FERREIRA, Lorena Ribeiro. "Engravidei, pari cavalos e aprendi a voar sem asas: reflexões acerca da afetividade e solidão da mulher negra". Darandina Revista Eletrônica, v. 11, n. 2. p. 1-18, 2018. Disponível em http://www.ufjf.br/darandina/files/2018/12/Artigo-LorenaRibeiro.pdf. Acesso em 13/ 12/2018. ISSN: 1983-8379

FOUCAULT, Michel. "Les tecnhiniques de soi”. In: FOUCAULT, Michel. M. Dits et écrits. Paris: Gallimard, 1994. p. 783-813.

GAULEJAC, Vincent de. As Origens da Vergonha. São Paulo: Via Lettera, 2006.

GONÇALVES FILHO, José Moura. "A dominação racista: o passado presente". In: KON, Noemi Moritz; SILVA, Maria Lúcia da; ABUD, Cristiane Curi (Orgs.). O racismo e o negro no Brasil: questões para a psicanálise. São Paulo: Perspectiva, 2017. p. 143-159. (cap. 8)

GONZALEZ, Lélia. "Racismo e sexismo na cultura brasileira". In: GONZALEZ, Lélia. Lélia Gonzalez Primavera para as rosas negras. São Paulo: Diáspora Africana, 2018. p. 190-214. (Coletânea organizada e editada pela UCPA União dos Coletivos Pan-Africanistas) 
INSTITUTO PATRÍCIA GALVÃO. Dossiê Violência Contra Mulheres, 2016. Disponível em http:// www.agenciapatriciagalvao.org.br/dossie/violencias/violencia-e-racismo/. Acesso em 03/10/2016.

LAPLANCHE, Jean; PONTALIS, Jean-Bertrand Lefebvre. Vocabulário da Psicanálise. 2. ed. São Paulo: Martins Fontes, 1995. 552p.

LIMA, Gabriela Quadros; WERLANG, Blanca Susana Guevara. "Mulheres que sofrem violência doméstica: contribuições da psicanálise". Psicologia em Estudo, Maringá, v. 16, n. 4, p. 51 1-520, 2011.

MACHADO, Lia Zanotta; MAGALHÃES, Maria Tereza Bossi. Violência Conjugal: os Espelhos e as Marcas. Brasília: EDUnB, 1998.

MEZAN, Renato. Psicanálise, Judaísmo: Ressonâncias. Campinas: Escuta, 1986.

MUNANGA, Kabengele. "As ambiguidades do racismo à brasileira". In: KON, Noemi Moritz; SILVA, Maria Lúcia da; ABUD, Cristiane Curi (Orgs.). O racismo e o negro no Brasil: questões para a psicanálise. São Paulo: Perspectiva, 2017. p. 33-44. (cap. 1)

O GLOBO. "Filha de Giovanna Ewbank e Bruno Gagliasso é vítima de racismo". O Globo, 27/1 1/ 2017. Disponível em https://oglobo.globo.com/rio/filha-de-giovanna-ewbank-brunogagliassovitima-de-racismo-22117146. Acesso em 14/01/2018.FREUD, Sigmund. Obras Psicológicas Completas de Sigmund Freud. Rio de Janeiro: Imago, 1969. (Edição Standard Brasileira)

OLIVEIRA, Fátima. Saúde da população negra: Brasil ano 2001. Brasília: Organização PanAmericana da Saúde, 2003.

OLIVEIRA, Fátima. "Avaliando e elencando os desafios". In: SEMINÁRIO NACIONAL VIOLÊNCIA CONTRA A MULHER - SAÚDE UM OLHAR DA MULHER NEGRA, 1, 2004, Santos, Casa de Cultura da Mulher Negra. Anais... Belo Horizonte: Casa de Cultura da Mulher Negra, 2004.

PEREIRA, Bruna Cristina Jaquetto. "Tramas e dramas de gênero e de cor: a violência doméstica e familiar contra mulheres negras". 2013. 132f. Dissertação (Mestrado em Sociologia) - Departamento de Sociologia, Universidade de Brasília, Brasília, 2013.

PINA, Rute. "Lei Maria da Penha completa 10 anos como referência, mas com problemas de execução". Brasil de Fato, São Paulo, 05/08/2016. Disponível em https://www.brasildefato.com.br/ 2016/08/05/lei-maria-da-penha-completa-10-anoscomo-referencia-mas-comproblemas-deexecucao. Acesso em 04/04/2017.

RATTS, Alex; RIOS, Flávia. Lélia Gonzalez. São Paulo: Selo Negro; Summus, 2010. 173p.

ROMIO, Jackeline Aparecida Ferreira. "A Vitimização de Mulheres por Agressão Física, segundo Raça/Cor no Brasil". In: MARCONDES, Mariana; PINHEIRO, Luana, et al. (Orgs.). Dossiê Mulheres Negras: Retrato das Condições De Vida Das Mulheres Negras No Brasil. Brasília: Instituto de Pesquisa Econômica Aplicada (IPEA), p. 133-158, 2013.

SANTOS, Lílian Mann dos. "A situação econômica como fator agravante da violência doméstica: um estudo da Delegacia da Mulher de Florianópolis". Revista Katálysis, Florianópolis, n. 4, p. 113 121 , jan. 1999. Disponível em https://periodicos.ufsc.br/index.php/katalysis/article/view/6263. Acesso em 23/01/2018. doi: http://dx.doi.org/10.1590/\%x

SÃO PAULO. Imprensa Oficial Do Estado De São Paulo. Os Efeitos Psicossociais do Racismo. São Paulo: Imprensa Oficial do Estado de São Paulo; Instituto AMMA Psique e Negritude, 2008.

SARTRE, Jean-Paul. Reflexões sobre o Racismo. São Paulo: Guinsburg; Difusão Europeia do Livro, 1965.

SCHUCMAN, Lia Vainer; GONÇALVES, Mônica Mendes. "Racismo na família e a construção da negritude: embates e limites entre a degradação e a positivação na constituição do sujeito". Revista do Programa de Pós-Graduação em Relações Étnicas e Contemporaneidade - UESB, Vitória da Conquista, v. 2, n. 4, p. 61-83, dezembro 2017.

SILVA, Maria Lúcia da. "Racismo no Brasil: Questões para psicanalistas brasileiros". In: KON, Noemi Moritz; SILVA, Maria Lúcia da; ABUD, Cristiane Curi (Orgs.). O racismo e o negro no Brasil: questões para a psicanálise. São Paulo: Perspectiva, 2017. p. 71-89. (cap. 4)

SOUZA, Claudete Alves da Silva. A solidão da mulher negra - sua subjetividade e seu preterimento pelo homem negro na cidade de São Paulo. 2008. Dissertação (Mestrado em Ciências Sociais) - 
Pontifícia Universidade Católica de São Paulo, São Paulo, SP, Brasil.

SOUZA, Neusa Santos. Tornar-se negro. Rio de Janeiro: Graal, 1983. 89p.

VANUCCHI, Maria Beatriz Costa Carvalho. "A violência nossa de cada dia: o racismo à brasileira". In: KON, Noemi Moritz; SILVA, Maria Lúcia da; ABUD, Cristiane Curi (Orgs.). O racismo e o negro no Brasil: questões para a psicanálise. São Paulo: Perspectiva, 2017. p. 59-70. (cap. 3)

WERNECK, Jurema. "Mulheres negras e violência no Rio de Janeiro". In: CASTRO, Lúcia Maria Xavier de; CALASANS, Myllena; REIS, Sarah (Orgs.). Mulheres de Brasília e do Rio de Janeiro no Monitoramento da Política Nacional de Enfrentamento à Violência contra as Mulheres. Rio de JaneirO: CRIOLA; CFEMEA, 2010.

WIEVIORKA, Michel. O Racismo: uma Introdução. São Paulo: Perspectiva, 2007.

Christiane Carrijo (christiane.carrijo@unesp.br) é psicóloga, mestre em Psicologia Clínica pela PUC-SP, doutora em Filosofia pela UFSCar, Professora Assistente do Departamento de Psicologia da UNESP-Bauru. Orientadora do Projeto que deu origem ao presente artigo. Suas pesquisas se concentram na teoria e clínica psicanalítica, com ênfase nos estudos e intervenções nas áreas da Saúde, na Violência Sexual contra Crianças e Adolescentes e na Violência contra a Mulher.

Paloma Afonso Martins (paloma.martins@unesp.br) é psicóloga pela Unesp de Bauru, bolsista FAPESP de iniciação científica com a pesquisa "A Violência do Racismo Contra Mulheres Negras Vítimas de Violência Doméstica: Rasgando os Véus"; participante do projeto de Extensão "Saraus e Contação de Histórias: Psicanálise e arte como estratégia clínica e política na atenção à infância", de 2014 a 2017, sendo bolsista PROEX nos anos de 2015 e 2017, e aluna do Programa de Especialização em Psicologia da Infância pela Unifesp.

\section{COMO CITAR ESSE ARTIGO DE ACORDO COM AS NORMAS DA REVISTA}

MARTINS, Paloma Afonso; CARRIJO, Christiane. "A Violência Doméstica e Racismo Contra Mulheres Negras". Revista Estudos Feministas, Florianópolis, v. 28, n. 2, e60721, 2020.

\section{CONTRIBUIÇÃO DE AUTORIA}

Christiane Carrijo: ideia da estrutura do texto (a pesquisa possui muitos dados e o artigo é apenas uma parte dela), revisão final do texto com algumas alterações da escrita e poucos acréscimos, formatação nas normas, redação do resumo no português e inglês.

Paloma Afonso Martins: autora da pesquisa que deu origem ao artigo, responsável pela pesquisa de campo; no presente artigo, contribuiu com a estruturação do texto, sendo responsável pela escrita do mesmo e organização da bibliografia.

O artigo original foi traduzido para o inglês por Tony O'Sullivan.

\section{FINANCIAMENTO}

O presente artigo é fruto de uma pesquisa de Iniciação Científica financiada pela FAPESP "A violência do racismo contra mulheres negras vítimas de violência doméstica: rasgando os véus", com vigência de julho a dezembro de 2017.

\section{CONSENTIMENTO DE USO DE IMAGEM}

Não se aplica.

APROVAÇÃO DE COMITÊ DE ÉTICA EM PESQUISA

Número do Parecer da Plataforma Brasil: 1.958.956.

CONFLITO DE INTERESSES

Não se aplica. 


\section{LICENÇA DE USO}

Este artigo está licenciado sob a Licença Creative Commons CC-BY International. Com essa licença você pode compartilhar, adaptar, criar para qualquer fim, desde que atribua a autoria da obra.

\section{HISTÓRICO}

Recebido em 17/12/2018

Reapresentado em 16/08/2019

Reapresentado em 15/09/2019

Aprovado em 22/11/2019

\section{Errata}

Neste artigo, os nomes dos autores aparecem na página 1, na legenda no topo das páginas pares, na minibiografia e na contribuição da autoria, na página 13. Em todos esses locais

Onde se lia:

Christiane Carrijo Eckhardt Mouammar

Leia-se:

Christiane Carrijo 